\title{
Manejo Químico de Convolvulaceae e Euphorbiaceae em Cana-de-Açúcar em Período de Estiagem ${ }^{1}$
}

\author{
Chemical Management of Convolvulaceae and Euphorbiaceae in Sugarcane during Dry Season
}

\author{
AZANIA, C.A.M. ${ }^{2}$, AZANIA, A.A.P.M. ${ }^{3}$, PIZZO, I.V. ${ }^{4}$, SCHIAVETTO, A.R. ${ }^{5}$, ZERA, F.S. ${ }^{6}$, \\ MARCARI, M.A. ${ }^{7}$ e SANTOS, J.L. ${ }^{8}$
}

\begin{abstract}
RESUMO - As famílias Convolvulaceae e Euphorbiaceae possuem diferentes espécies que infestam os canaviais de forma rápida e agressiva, especialmente em áreas cobertas pela palha remanescente da colheita que não foram queimadas. Essa infestação, associada às extensas áreas de cultivo, tem dificultado a operacionalidade do manejo químico exclusivamente durante a estação chuvosa do ano, levando aos produtores a necessidade de aplicar os herbicidas também no periodo de estiagem. Nesse contexto, o presente trabalho objetivou estudar a persistência dos herbicidas aplicados durante o período de estiagem em resistir às intempéries climáticas até o início da estação chuvosa, avaliando-se o controle sobre as espécies dos gêneros de Ipomoea, Merremia e Euphorbia. O delineamento experimental foi em blocos casualizados com 42 tratamentos, distribuídos em esquema de parcelas subdivididas com seis repetições. Os herbicidas amicarbazone $\left(1.050 \mathrm{~g} \mathrm{ha}^{-1}\right)$, imazapic $\left(1.22,5 \mathrm{~g} \mathrm{ha}^{-1}\right)$, sulfentrazone $\left(600 \mathrm{~g} \mathrm{ha}^{-1}\right)$ e as associações clomazone $\left(1.000 \mathrm{~g} \mathrm{ha}^{-1}\right)+$ hexazinone (250 $\left.\mathrm{g} \mathrm{ha}^{-1}\right)$, sulfentrazone $\left(600 \mathrm{~g} \mathrm{ha}^{-1}\right)+\operatorname{diurom}\left(936 \mathrm{~g} \mathrm{ha}^{-1}\right)+$ hexazinone $\left(264 \mathrm{~g} \mathrm{ha}^{-1}\right)$, sulfentrazone (500 $\left.\mathrm{g} \mathrm{ha}^{-1}\right)+$ amicarbazone (700 $\mathrm{g} \mathrm{ha}^{-1}$ ) e testemunha foram alocados nas parcelas. As espécies Ipomoea nil, I. hederifolia, I. quamoclit, I. grandifolia, Merremia aegyptia e Euphorbia heterophylla foram semeadas diretamente no solo, cobertas com o equivalente a $15 \mathrm{t} \mathrm{ha}^{-1}$ de palha de cana-de-açúcar e alocadas nas subparcelas. Após a aplicação dos herbicidas, registraram-se 70 dias de ausência de chuvas e o estresse hídrico impossibilitou a avaliação de controle, devido à não emergência das plantas daninhas em todos os tratamentos. Entretanto, com o início da estação chuvosa aos 90 dias após o tratamento, iniciaram-se as avaliações de eficácia devido à emergência das plantas daninhas. Aos 150 DAT (dias após os tratamentos) os herbicidas sulfentrazone e sulfentrazone associado a amicarbazone foram os mais persistentes e apresentaram média de eficácia de controle superior a $85 \%$, considerando todas as espécies, quando comparada à da testemunha.
\end{abstract}

Palavras-chave: Euphorbia, herbicidas, Ipomoea, Merremia, Saccharum spp.

\begin{abstract}
Different species of the Convolvulaceae and Euphorbiaceae family infest sugarcane culture rapidly and aggressively, especially in areas covered by the unburned straw remaining from the harvest. This infestation, combined with extensive cultivation areas, have made it difficult to manage the chemical application exclusively during the rainy season of the year, forcing producers to apply the herbicides also during the drought period. Within this context, this work aimed to study the persistence of the herbicides applied during drought in resisting bad weather until the start of the rainy season, by evaluating the control over the species of the genera Ipomoea, Merremia and Euphorbia. The experimental design was a randomized block with 42 treatments distributed in a split-plot with six replications. The herbicides amicarbazone (1050 $\left.\mathrm{g} \mathrm{ha}^{-1}\right)$; imazapic (122,5 $\left.\mathrm{g} \mathrm{ha} \mathrm{h}^{-1}\right)$; sulfentrazone (600 $\left.\mathrm{g} \mathrm{ha}^{-1}\right)$ and associations clomazone (1000 $\left.\mathrm{g} \mathrm{ha}^{-1}\right)+$ hexazinone $\left(250 \mathrm{~g} \mathrm{ha}^{-1}\right)$; sulfentrazone $\left(600 \mathrm{~g} \mathrm{ha}^{-1}\right)+\operatorname{diurom}\left(936 \mathrm{~g} \mathrm{ha}^{-1}\right)+$ hexazinone $\left(264 \mathrm{~g} \mathrm{ha}^{-1}\right)$; sulfentrazone $(500 \mathrm{~g} \mathrm{ha}$ ) + amicarbazone (700 $\left.\mathrm{g} \mathrm{ha}^{-1}\right)$ and control were allocated to the plots. The species Ipomoea nil,
\end{abstract}

Recebido para publicação em 18.11.2008 e na forma revisada em 13.11.2009

2 PqC Dr., Instituto Agronômico/Centro de Cana, Rodov. Pref. Antonio Duarte Nogueira, km 321, 14032-800 Ribeirâo Preto-SP, <azania@iac.sp.gov.br>; ${ }^{3} \mathrm{PqC}$ Dra., Voluntária do Instituto Agronômico/Centro de Cana; ${ }^{4}$ Bolsista Pibic; ${ }^{5}$ Mestranda da FCAVJ/ UNESP em Genética e Melhoramento de Plantas, Via de Acesso Prof. Paulo Donato Castellane s/ n, 14884-900 Jaboticabal-SP; ${ }^{6}$ Mestrando do Instituto Agronômico; ${ }^{7}$ Graduando em Engenharia Agronômica pelo CUML; ${ }^{8}$ Mestrando da FCAVJ/UNESP.

Planta Daninha, Viçosa-MG, v. 27, n. 4, p. 841-848, 2009 


\begin{abstract}
I. hederifolia, I. quamoclit, I. grandifolia, Merremia aegyptia and Euphorbia heterophylla were sown directly into the soil, covered with the equivalent of $15 t$ ha $^{-1}$ sugarcane straw and allocated to the sub-plots. After herbicide application, 70 days without rain were recorded, with water stress rendering evaluation impossible, since no weed emergence occurred in all treatments. However, in the beginning of the rainy season 90 days after treatment, evaluations on the effectiveness of weed emergence could be carried out. At 150 DAT (days after treatments), the herbicides sulfentrazone and sulfentrazone, associated with amicarbazone, were the most persistent and presented an effective control mean over $85 \%$, considering all species when compared with the control.
\end{abstract}

Keywords: Euphorbia, herbicides, Ipomoea, Merremia, Saccharum spp.

\section{INTRODUÇÃO}

Para a cultura da cana-de-açúcar existem diferentes herbicidas seletivos e com espectro de ação sobre diferentes plantas daninhas (Brasil, 2008), mas, independentemente da flora daninha presente, a maioria dos herbicidas necessita de umidade no solo para que suas moléculas possam se movimentar pela solução do solo e ser absorvidas pelas sementes das plantas daninhas (Martini \& Durigan, 2004). Assim, o manejo químico é mais eficaz quando realizado durante a estação das chuvas, pois a água disponivel no solo e o intenso desenvolvimento das plantas daninhas favorecem a absorção dos herbicidas.

Entretanto, devido à expansão do setor sucroalcooleiro $(3,95$ milhões de hectares, segundo Unica, 2008), os produtores têm dificuldade em concentrar as aplicações de herbicidas somente na estação chuvosa, o que os leva a aplicá-los também no período de estiagem, a fim de que persistam no solo até o início da estação chuvosa. Os herbicidas aplicados em condições de estresse hídrico podem ficar depositados sobre a camada de palha e não chegar ao solo; ficam, portanto, expostos à decomposição, volatilização ou fotodecomposição (Locke \& Bryson, 1997; Simoni et al., 2006). Para Lamoreaux et al. (1993), a lixiviação do herbicida desde a superfície da palha até atingir o solo depende da uniformidade da camada de palha, da solubilidade do produto e do período sem chuvas a partir da aplicação.

A eficácia de controle das plantas daninhas com herbicidas residuais, seja na estação chuvosa ou seca do ano, é influenciada pela umidade, pelos teores de argila e matéria orgânica, pelo $\mathrm{pH}$ ou pela cobertura do solo com palha e por características físico-químicas dos herbicidas, como a solubilidade e pressão de vapor. Esses fatores podem influenciar também os processos de adsorção, lixiviação e degradação biológica, com consequente reflexo sobre a persistência desses compostos no solo e na absorção pelas raízes de plantas daninhas (Walker et al., 1992).

A preocupação dos produtores em aplicar os herbicidas mesmo em períodos de estiagem se intensifica mais em áreas infestadas com espécies dos gêneros Ipomoea, Merremia e Euphorbia. Essas plantas daninhas são agressivas e, segundo Milholon et al. (citado por Siebert et al., 2004), podem proporcionar até $24 \%$ de prejuízo na produtividade da cana, em condições de clima temperado. Outro fator que desperta preocupação entre os produtores é o fato de que a presença das espécies dos gêneros Ipomoea e Merremia (Correia \& Durigan, 2004) e Euphorbia (Martins et al., 1999) se intensifica em cultivos que têm o solo coberto por palha.

A característica principal das convolvuláceas é que são plantas de caules e ramos volúveis, que conferem o hábito de crescimento trepador (Kissmann \& Groth, 1999). Essas espécies causam prejuízos à cultura da cana-de-açúcar, especialmente em canaviais colhidos sem a prévia queima. Segundo Azania et al. (2002), as convolvuláceas são capazes de emergirem em camadas de palha de até $15 \mathrm{t} \mathrm{ha}^{-1}$. Entretanto, à medida que o sistema radicular dessas plantas se desenvolve, aumenta a competição por água e nutrientes no solo com a cultura. A competição ganha maior importância quando as infestantes se envolvem nos colmos e alcançam o ápice das 
plantas de cana-de-açúcar, dificultando a absorção de luz, com consequente prejuízo à fotossintese.

Nessa fase, Elmore et al. (1990) comentaram que o envolvimento dos colmos de cana pelas plantas de corda-de-viola reduz a eficiência operacional das colhedoras. Na ocasião da colheita, se as plantas apresentarem sementes, elas podem ter seu espesso tegumento (Defelice, 2001) danificado pelo atrito no interior das colhedoras, com posterior disseminação pelo canavial.

A espécie Euphorbia heterophylla tem hábito de crescimento ramificado e se dissemina por sementes, as quais apresentam considerável dormência. Quando maduras, essas sementes são lançadas à distância da planta-mãe (Kissmann \& Groth, 1999). As plântulas de E. heterophylla, assim como as convolvuláceas, também são capazes de emergir em camadas de palha de até $15 \mathrm{t} \mathrm{ha}^{-1}$ (Martins et al., 1999); contudo, as plantas dessa espécie também tiveram sua emergência e desenvolvimento observados tanto em áreas sem palha como naquelas com a presença desta (Medeiros \& Christoffoleti, 2001). A partir de $20 \mathrm{t} \mathrm{ha}^{-1}$, a palha pode suprimir a espécie e prejudicar a eficácia de alguns herbicidas, de acordo com Monquero et al. (2007).

Considerando a necessidade de aplicação dos herbicidas durante o período de estiagem e a importância das plantas daninhas das famílias Convolvulaceae e Euphorbiaceae, este trabalho objetivou estudar a persistência dos herbicidas aplicados durante o período de estiagem até o início da estação chuvosa, avaliando-se a eficácia de controle sobre espécies dos gêneros Ipomoea, Merremia e Euphorbia.

\section{MATERIAL E MÉTODOS}

Este trabalho foi realizado no Centro de Cana do Instituto Agronômico de Campinas, no município de Pradópolis-SP, em um Latossolo Vermelho textura argilosa não cultivado, com $13,5 \%$ de silte, $49,9 \%$ de argila e $36,5 \%$ de areia. O clima predominante na região, de acordo com a classificação de Köppen, é o Aw, tropical com estação seca de inverno. Segundo o Ciiagro (2008), nos últimos 17 anos, a precipitação anual média da região foi de $1.485 \mathrm{~mm}$, com temperatura média anual de $22,9{ }^{\circ} \mathrm{C}$ e extremos de $298,5 \mathrm{~mm}$ com $24,8{ }^{\circ} \mathrm{C}$ e $14,7 \mathrm{~mm}$ com $19,8^{\circ} \mathrm{C}$, respectivamente, para o mês mais úmido e seco (Tabela 1).

O experimento foi instalado durante o período seco do inverno, em 10/8/2007, utilizando-se o delineamento em blocos casualizados, em esquema de parcelas subdivididas com 42 tratamentos em seis repetições. As parcelas com $4,5 \mathrm{~m}^{2}$ receberam a aplicação dos tratamentos herbicidas e de uma testemunha sem aplicação, e nas subparcelas de $0,75 \mathrm{~m}^{2}$ foram alocadas as espécies de plantas daninhas, sendo uma espécie por subparcela.

O lote de sementes de todas as espécies apresentou viabilidade de $98 \%$, a qual foi obtida antes da semeadura, amostrando-se quatro repetições de 100 sementes para cada espécie. As sementes, assim amostradas, foram cortadas longitudinalmente e acondicionadas em vidros âmbar e imersas em solução de cloreto de 2,3,5 trifeniltetrazólio $0,1 \%$. Depois de transcorridas 12 horas, foi observado e contado o número de sementes com embrião que apresentavam coloração rósea (indicador da viabilidade) e, por simples regra de três, chegou-se à porcentagem de viabilidade do lote.

As espécies estudadas foram Ipomoea nil, Ipomoea hederifolia, Ipomoea quamoclit, Ipomoea grandifolia, Merremia aegyptia e Euphorbia heterophylla, semeadas nas subparcelas com 24 horas de antecedência à aplicação dos herbicidas. A quantidade de sementes utilizada foi baseada no teste de germinação realizado pelo fornecedor, de modo que $1,92 \mathrm{~g}$ de I. hederifolia, 0,48 g de I. grandifolia, 0,86 g de

Tabela 1 - Precipitações e temperaturas médias ocorridas durante o período de avaliação do experimento. Ribeirão Preto-SP, 2007

\begin{tabular}{|l|r|r|c|c|}
\hline \multirow{2}{*}{ Mês } & \multicolumn{2}{|c|}{ Precipitação (mm) } & \multicolumn{2}{c|}{ Temperatura média ( C) } \\
\cline { 2 - 5 } & $2007 / 08$ & $\begin{array}{c}\text { média } \\
\text { histórica }\end{array}$ & 2007 & $\begin{array}{c}\text { média } \\
\text { histórica }\end{array}$ \\
\hline Agosto & 0 & 14,4 & 25,5 & 21,6 \\
\hline Setembro & 0 & 60,6 & 25,0 & 23,2 \\
\hline Outubro & 55 & 108,5 & 26,1 & 24,6 \\
\hline Novembro & 153 & 182,6 & 23,9 & 24,3 \\
\hline Dezembro & 197 & 247,3 & 25,2 & 24,6 \\
\hline Janeiro & 350 & 298,5 & 24,0 & 24,7 \\
\hline
\end{tabular}

Fonte: IAC/Ciiagro (2008); média histórica dos últimos 17 anos. 
I. quamoclit, 1,53 g de $M$. cissoides e 0,28 g de $E$. heterophylla foram suficientes para proporcionar a emergência de no mínimo 25 plantas de cada espécie por subparcela.

Os herbicidas utilizados foram amicarbazone (1.050 $\left.\mathrm{g} \mathrm{ha}^{-1}\right)$, imazapic (122,5 $\left.\mathrm{g} \mathrm{ha}^{-1}\right)$, sulfentrazone $\left(600 \mathrm{~g} \mathrm{ha}^{-1}\right)$ e as associações clomazone $\left(1.000 \mathrm{~g} \mathrm{ha}^{-1}\right)+$ hexazinone $\left(250 \mathrm{~g} \mathrm{ha}^{-1}\right)$, sulfentrazone $\left(600 \mathrm{~g} \mathrm{ha}^{-1}\right)+$ diurom (936 $\left.\mathrm{g} \mathrm{ha}^{-1}\right)+$ hexazinone (264 $\left.\mathrm{g} \mathrm{ha}^{-1}\right)$, sulfentrazone $\left(500 \mathrm{~g} \mathrm{ha}^{-1}\right)+$ amicarbazone (700 $\left.\mathrm{g} \mathrm{ha}^{-1}\right)$ e testemunha, aplicados em préemergência das plantas daninhas, com presença de camada de palha equivalente a $15 \mathrm{t} \mathrm{ha}^{-1}$. A escolha pelos tratamentos herbicidas se deu em função de serem amplamente utilizados pelos produtores de cana-de-açúcar, sobretudo em áreas infestadas por espécies dos gêneros Ipomoea e Merremia.

A aplicação teve início às $17 \mathrm{~h} 25$ e terminou às $18 \mathrm{~h}$. No início desse período foram registrados $25,8{ }^{\circ} \mathrm{C}$ de temperatura média do ar, $45,6 \%$ de umidade relativa e ausência de ventos. No final desse período, registraram-se $21,2{ }^{\circ} \mathrm{C}$ de temperatura média do ar, $55,8 \%$ de umidade relativa e ausência de ventos. Foi utilizado um pulverizador costal pressurizado, com barra de $2 \mathrm{~m}$ e quatro bicos jato leque TT110/02, espaçados de $0,50 \mathrm{~cm}$, trabalhando com 35 libras pol-1 $^{-2}$, proporcionando volume de calda aproximado de $267 \mathrm{~L} \mathrm{ha}^{-1}$.

As avaliações ocorreram aos 30, 60, 90, 120 e 150 DAT em cada subparcela tratada com herbicida. Para avaliar a eficácia de controle sobre as plantas daninhas, utilizou-se de uma escala variando de 0 a $100 \%$, em que 0 corresponde à ausência de controle e 100 ao total controle das plantas daninhas (Rolim, 1989). $\mathrm{Na}$ última avaliação, as plantas de todas as subparcelas foram coletadas, lavadas, secas em temperatura ambiente e na sombra e, após acondicionamento em sacos de papel, submetidas à estufa de circulação forçada com renovação de ar a $70{ }^{\circ} \mathrm{C}$, até peso constante.

As variáveis obtidas nos tratamentos herbicidas foram submetidas ao teste $\mathrm{F}$ para avaliar o efeito dos tratamentos; posteriormente, na comparação das médias dos tratamentos, utilizou-se o teste de Tukey a $5 \%$ de probabilidade.

\section{RESULTADOS E DISCUSSÃO}

No mês de outubro, início da primavera, mais particularmente no dia 20/10/2007, cessou-se o período de 70 dias de estiagem desde a aplicação dos herbicidas, com o retorno da estação chuvosa. A partir dessa data, as chuvas tornaram-se mais constantes (Tabela 1), e no dia $10 / 11 / 2008$, quando se completaram 90 DAT, foi possivel observar a emergência das plantas daninhas.

Aos 90 DAT, as sementes germinaram e superaram o obstáculo físico da camada de palha, expondo as partes aéreas à superfície, conforme também observado nos trabalhos de Martins et al. (1999) e Azania et al. (2002).

As espécies I. hederifolia, I. quamoclit, I. grandifolia e E. heterophylla apresentaram diminuição na porcentagem de cobertura ao se compararem as avaliações aos 90 e aos 120 DAT, porém aos 150 DAT apresentavamse novamente com maiores percentuais de cobertura (Tabela 2).

Tabela 2 - Valores médios percentuais de cobertura das plantas daninhas em relação às testemunhas nas subparcelas $\left(0,75 \mathrm{~m}^{2}\right) \mathrm{em}$ diferentes épocas de avaliação e a respectiva massa seca final. Ribeirão Preto-SP, 2008

\begin{tabular}{|c|c|c|c|c|c|c|}
\hline \multirow{3}{*}{ Espécie } & \multicolumn{6}{|c|}{ Dias após tratamento } \\
\hline & \multicolumn{5}{|c|}{ cobertura $(\%)$} & \multirow{2}{*}{$\begin{array}{c}\text { massa seca }(\mathrm{g}) \\
150 \\
(10 / 01)\end{array}$} \\
\hline & $\begin{array}{c}30 \\
(10 / 09)\end{array}$ & $\begin{array}{c}60 \\
(10 / 10)\end{array}$ & $\begin{array}{c}90 \\
(10 / 11)\end{array}$ & $\begin{array}{c}120 \\
(10 / 12)\end{array}$ & $\begin{array}{c}150 \\
(10 / 01)\end{array}$ & \\
\hline 1. Ipomoea nil & 0 & 0 & 55,83 & 81,67 & 100,00 & 97,46 \\
\hline 2. Ipomoea hederifolia & 0 & 0 & 82,50 & 74,17 & 81,67 & 104,69 \\
\hline 3. Ipomoea quamoclit & 0 & 0 & 62,50 & 50,00 & 55,00 & 40,40 \\
\hline 4. Ipomoea grandifolia & 0 & 0 & 63,33 & 60,00 & 70,83 & 66,49 \\
\hline 5. Merremia aegyptia & 0 & 0 & 40,83 & 65,00 & 71,67 & 137,00 \\
\hline 6. Euphorbia heterophylla & 0 & 0 & 85,00 & 50,00 & 50,00 & 41,96 \\
\hline Média geral & 0 & 0 & 65,00 & 63,47 & 71,53 & 81,33 \\
\hline
\end{tabular}


Aos 90 DAT, aproximadamente 65\% das áreas testemunhas apresentavam-se cobertas pelas plantas daninhas semeadas; se as subparcelas não tivessem sido manejadas pelos herbicidas propostos, todas apresentariam porcentagens de cobertura próximas a esse valor. Entretanto, todos os herbicidas controlaram mais de $85 \%$ da infestação observada com relação à testemunha, exceto imazapic, que controlou apenas $60,69 \%$ em comparação à testemunha (Tabela 3).

Segundo Rolim (1989), 85\% é considerado controle suficiente (S) sobre uma comunidade infestante, e porcentagens de controle abaixo desse valor podem ser apontadas como não satisfatórias. A diferença observada entre o controle proporcionado pelos herbicidas e pelo imazapic foi significativa (Tabela 3).

O imazapic é um herbicida tido como seletivo à cana-de-açúcar e possui persistência no solo de até 180 dias (Brasil, 2008); sua insuficiente eficácia pode ser explicada pela dose utilizada. Segundo a recomendação indicada no passado (Azania, 2000) e adotada no presente estudo, a dose do produto era de 105 a $122,5 \mathrm{~g} \mathrm{ha}^{-1}$ para soqueiras infestadas com plantas daninhas anuais; atualmente, a dose do produto, segundo Brasil (2008), pode se estender até $371 \mathrm{~g} \mathrm{ha}^{-1}$. O uso de imazapic a $175 \mathrm{~g} \mathrm{ha}^{-1}$ ainda é comum entre os produtores; por se tratar de uma dose intermediária também recomendada, optou-se pelo seu estudo.

Quanto às plantas daninhas, a maioria das espécies recebeu controle suficiente (S), porém I. grandifolia e Euphorbia heterophylla apresentaram controle duvidoso (D), com 81,94 e $79,31 \%$ aos 90 DAT. A espécie de $E$. heterophylla foi a mais dificil de se controlar com os herbicidas, em todas as épocas de avaliação. Segundo Monquero et al. (2007), $E$. heterophylla não foi controlada satisfatoriamente pelos herbicidas quando estes foram aplicados sobre camadas de palha em quantidade superior a $15 \mathrm{t} \mathrm{ha}^{-1}$.

Aos 120 DAT, todos os herbicidas apresentaram controles estatisticamente similares, inclusive o imazapic, cuja eficácia de controle foi maior que $85 \%$, embora seu percentual de eficácia ainda tenha ficado entre os menores. Entretanto, eficácia ainda menor foi observada para a formulação de clomazone + hexazinone, permanecendo com controle inferior a $85 \%$ e considerado como duvidoso (D). A formulação de clomazone + hexazinone é recente no mercado e, por conseguinte, existe escassa literatura a respeito.

Entre as espécies de plantas daninhas, aos 120 DAT, somente Euphorbia heterophylla recebeu controle duvidoso (D), diferindo de I. quamoclit, com $91,94 \%$, e de $M$. aegyptia, com $89,44 \%$ de controle (Tabela 3). Todavia, pela escala de notas, exceto para Euphorbia heterophylla, todas as espécies apresentaram controle suficiente (S).

Os herbicidas proporcionaram menor eficácia de controle aos 150 DAT, quando comparado com as avaliações anteriores (Tabela 3 ). Segundo Brasil (2008), a persistência desses produtos no solo pode atingir entre 150 e 180 dias, e, considerando a data de realização da última avaliação, pôde-se deduzir que o período de persistência aproximava-se do final. Essa questão, associada à dormência das sementes com os consequentes fluxos de emergência das plântulas, talvez tenha sido um dos principais motivos da menor eficácia nesse período.

Não se constataram diferenças para massa seca entre os fatores herbicidas e as espécies aos 150 DAT. Nessa avaliação, os herbicidas com eficácia superior a $85 \%$ foram apenas sulfentrazone e sua associação com amicarbazone, com controle considerado suficiente (S), sendo todos os demais duvidosos (D). Negrisoli et al. (2004) também observaram resultados positivos com o uso de sulfentrazone sobre a palha de cana-de-açúcar, que resultou em excelente controle, atingindo $100 \%$ aos 28 dias após a aplicação para Ipomoea grandifolia. Em outro estudo, Negrisoli et al. (2007) verificaram que a espécie I. grandifolia mostrou-se mais sensivel ao amicarbazone, demonstrando elevada sensibilidade aos tratamentos com herbicidas.

De acordo com o desdobramento da interação herbicidas e espécies (Tabela 4), aos 150 DAT, o herbicida imazapic foi o que menos controlou Merremia aegyptia, com nota de controle classificada como mau (M), segundo a escala de notas de Rolim (1989). Menores controles também ocorreram com o tratamento em que se utilizou clomazone+hexazinone, 
Tabela 3 - Valores médios percentuais de controle de diferentes herbicidas em relação à testemunha, aplicados em pré-emergência das plantas daninhas nas subparcelas $\left(0,75 \mathrm{~m}^{2}\right)$ aos 90,120 e 150 DAT, na presença de palha de cana-de-açúcar durante a estação seca do ano. Ribeirão Preto-SP, 2008

\begin{tabular}{|c|c|c|c|c|c|c|c|}
\hline \multirow{2}{*}{\multicolumn{2}{|c|}{ Variável }} & \multicolumn{6}{|c|}{ Controle $(\%)$} \\
\hline & & \multicolumn{2}{|c|}{90 DAT } & \multicolumn{2}{|c|}{$120 \mathrm{DAT}$} & \multicolumn{2}{|c|}{150 DAT } \\
\hline Herbicida (A) & Dose $\left(\mathrm{g} \mathrm{ha}^{-1}\right)$ & & & & & & \\
\hline 1. amicarbazone & 1.050 & $88,06 \mathrm{a}$ & $\mathrm{S}$ & $88,61 \mathrm{a}$ & $\mathrm{S}$ & $79,39 \mathrm{ab}$ & $\mathrm{D}$ \\
\hline 2. imazapic & 122,5 & $60,69 \mathrm{~b}$ & I & $86,94 \mathrm{a}$ & $\mathrm{S}$ & $81,25 \mathrm{a}$ & $\mathrm{D}$ \\
\hline 3. sulfentrazone & 600 & $93,06 \mathrm{a}$ & $\mathrm{B}$ & $91,81 \mathrm{a}$ & $\mathrm{S}$ & $87,92 \mathrm{a}$ & $\mathrm{S}$ \\
\hline 4. clomazone + hexazinone & $1.000+250$ & $88,19 \mathrm{a}$ & $\mathrm{S}$ & $78,06 \mathrm{a}$ & $\mathrm{D}$ & $55,69 \mathrm{~b}$ & $\mathrm{M}$ \\
\hline 5. sulfentrazone + diuron + hexazinone & $600+(936+264)$ & $95,28 \mathrm{a}$ & $\mathrm{B}$ & $89,03 \mathrm{a}$ & $\mathrm{S}$ & $83,75 \mathrm{a}$ & $\mathrm{D}$ \\
\hline 6. sulfentrazone + amicarbazone & $500+700$ & $96,25 \mathrm{a}$ & $\mathrm{B}$ & $87,36 \mathrm{a}$ & $\mathrm{S}$ & $89,72 \mathrm{a}$ & $\mathrm{S}$ \\
\hline \multicolumn{2}{|c|}{ Testemunha ( $\%$ cobertura $)$} & \multicolumn{2}{|l|}{65,00} & \multicolumn{2}{|l|}{63,47} & \multicolumn{2}{|l|}{71,53} \\
\hline \multicolumn{2}{|c|}{ Espécie (B) } & & & & & & \\
\hline \multicolumn{2}{|l|}{ 1. Ipomoea nil } & $89,44 \mathrm{a}$ & $\mathrm{S}$ & $87,78 \mathrm{ab}$ & $\mathrm{S}$ & $83,33 \mathrm{a}$ & $\mathrm{D}$ \\
\hline \multicolumn{2}{|l|}{ 2. Ipomoea hederifolia } & $89,58 \mathrm{ab}$ & $\mathrm{S}$ & $86,39 \mathrm{ab}$ & $\mathrm{S}$ & $80,56 \mathrm{a}$ & $\mathrm{D}$ \\
\hline \multicolumn{2}{|l|}{ 3. Ipomoea quamoclit } & $91,67 \mathrm{a}$ & $\mathrm{S}$ & $91,94 \mathrm{a}$ & $\mathrm{S}$ & $85,69 \mathrm{a}$ & $\mathrm{S}$ \\
\hline \multicolumn{2}{|l|}{ 4. Ipomoea grandifolia } & $81,94 \mathrm{bc}$ & $\mathrm{D}$ & $86,81 \mathrm{ab}$ & $\mathrm{S}$ & $77,08 \mathrm{a}$ & $\mathrm{D}$ \\
\hline \multirow{2}{*}{\multicolumn{2}{|c|}{$\begin{array}{l}\text { 5. Merremia aegyptia } \\
\text { 6. Euphorbia heterophylla }\end{array}$}} & $89,58 \mathrm{ab}$ & $\mathrm{S}$ & $89,44 \mathrm{a}$ & $\mathrm{S}$ & $73,19 \mathrm{a}$ & $\mathrm{I}$ \\
\hline & & $79,31 \mathrm{c}$ & $\mathrm{D}$ & $79,44 \mathrm{~b}$ & $\mathrm{D}$ & $77,36 \mathrm{a}$ & $\mathrm{D}$ \\
\hline \multicolumn{2}{|l|}{$x_{1}$} & & & & & & \\
\hline \multicolumn{2}{|l|}{ Herbicidas $(\mathrm{A})$} & \multicolumn{2}{|c|}{$11,50^{* *}$} & \multicolumn{2}{|c|}{$2,01^{\mathrm{NS}}$} & \multicolumn{2}{|c|}{$4,98^{* *}$} \\
\hline \multicolumn{2}{|l|}{ Espécies (B) } & \multicolumn{2}{|c|}{$4,63^{* *}$} & \multicolumn{2}{|c|}{$3,22 * *$} & \multicolumn{2}{|c|}{$2,022^{\mathrm{NS}}$} \\
\hline \multicolumn{2}{|l|}{$\mathrm{AxB}$} & \multicolumn{2}{|c|}{$0,55^{\mathrm{NS}}$} & \multicolumn{2}{|c|}{$1,16^{\mathrm{NS}}$} & \multicolumn{2}{|c|}{$2,47^{* *}$} \\
\hline \multicolumn{2}{|l|}{ CV $(\%)$ parcela } & \multicolumn{2}{|c|}{27,08} & \multicolumn{2}{|c|}{22,79} & \multicolumn{2}{|c|}{41,72} \\
\hline \multicolumn{2}{|l|}{ CV $(\%)$ subparcela } & \multicolumn{2}{|l|}{16,09} & 16,18 & & 24,6 & \\
\hline
\end{tabular}

DAT (dias após tratamento). ${ }^{* *}$ significativo a $1 \%$ de probabilidade pelo teste $\mathrm{F}$. ${ }^{\mathrm{NS}}$ não significativo. $\mathrm{B}=$ bom, $\mathrm{E}=$ excelente, $\mathrm{D}=$ duvidoso, $\mathrm{S}$ = suficiente, $\mathrm{I}=$ insuficiente e $\mathrm{M}=$ mau, pela classificação de Rolim (1989).

Tabela 4 - Valores médios do desdobramento da interação AxB (herbicidas x espécies) para porcentagem de controle de plantas daninhas, com relação à testemunha, nas subparcelas $\left(0,75 \mathrm{~m}^{2}\right)$ aos $150 \mathrm{DAT}$

\begin{tabular}{|c|c|c|c|c|c|c|c|}
\hline \multirow[b]{2}{*}{ Espécie (B) } & \multicolumn{6}{|c|}{ Herbicida (A) } & \multirow[b]{2}{*}{$F$} \\
\hline & $\begin{array}{c}\text { amicarbazone } \\
1050 \mathrm{~g} \mathrm{ha}^{-1}\end{array}$ & $\begin{array}{l}\text { imazapic } \\
122,5 \mathrm{~g} \mathrm{ha}^{-1}\end{array}$ & $\begin{array}{l}\text { sulfentrazone } \\
600 \mathrm{~g} \mathrm{ha}^{-1}\end{array}$ & $\begin{array}{c}\text { clomazone }+ \\
\text { hexazinone } \\
1000 \mathrm{~g} \mathrm{ha}^{-1}+ \\
250 \mathrm{~g} \mathrm{ha}^{-1}\end{array}$ & $\begin{array}{c}\text { sulfentrazone }+ \\
\text { diuron+hexazinone } \\
\begin{array}{c}600 \mathrm{~g} \mathrm{ha}^{-1}+\left(936 \mathrm{~g} \mathrm{ha}^{-1}\right. \\
\left.+264 \mathrm{~g} \mathrm{ha}^{-1}\right)\end{array}\end{array}$ & $\begin{array}{c}\text { sulfentrazone }+ \\
\text { amicarbazone } \\
500 \mathrm{~g} \mathrm{ha}^{-1}+ \\
700 \mathrm{~g} \mathrm{ha}^{-1}\end{array}$ & \\
\hline Ipomoea nil & $73,00 \mathrm{Aa}(\mathrm{I})$ & $79,17 \mathrm{ABa}(\mathrm{D})$ & $90,00 \mathrm{Aa}(\mathrm{S})$ & $71,67 \mathrm{ABa}(\mathrm{I})$ & $95,00 \mathrm{Aa}(\mathrm{B})$ & $94,17 \mathrm{Aa}(\mathrm{B})$ & $1,32^{\mathrm{NS}}$ \\
\hline Ipomoea hederifolia & $85,83 \mathrm{Aa}(\mathrm{S})$ & $88,33 \mathrm{Aa}(\mathrm{S})$ & $95,83 \mathrm{Aa}(\mathrm{B})$ & $38,33 \mathrm{Cb}(\mathrm{P})$ & $86,67 \mathrm{Aa}(\mathrm{S})$ & $88,33 \mathrm{Aa}(\mathrm{S})$ & $5,22 * *$ \\
\hline Ipomoea quamoclit & $90,83 \mathrm{Aa}(\mathrm{S})$ & $90,00 \mathrm{Aa}(\mathrm{S})$ & $96,67 \mathrm{Aa}(\mathrm{MB})$ & $41,67 \mathrm{BCb}(\mathrm{M})$ & $98,33 \mathrm{Aa}(\mathrm{MB})$ & $96,67 \mathrm{Aa}(\mathrm{MB})$ & $5,65^{* *}$ \\
\hline Ipomoea grandifolia & $88,33 \mathrm{Aa}(\mathrm{S})$ & $87,50 \mathrm{Aa}(\mathrm{S})$ & $88,33 \mathrm{Aa}(\mathrm{S})$ & $35,83 \mathrm{Cb}(\mathrm{P})$ & $79,17 \mathrm{Aa}(\mathrm{D})$ & $83,33 \mathrm{Aa}(\mathrm{D})$ & $5,00 * *$ \\
\hline Merremia aegyptia & 71,67 Aab (I) & $51,67 \mathrm{Bb}(\mathrm{M})$ & $80,00 \mathrm{Aab}(\mathrm{D})$ & 71,67 ABab (I) & $70,00 \mathrm{Aab}(\mathrm{I})$ & 94,17 Aa (B) & $2,29^{*}$ \\
\hline Euphorbia heterophylla & $66,67 \mathrm{Aa}(\mathrm{I})$ & $90,83 \mathrm{Aa}(\mathrm{S})$ & $76,67 \mathrm{Aa}(\mathrm{D})$ & $75,00 \mathrm{Aa}(\mathrm{I})$ & $73,33 \mathrm{Aa}(\mathrm{I})$ & $81,67 \mathrm{Aa}(\mathrm{D})$ & $0,80^{\mathrm{NS}}$ \\
\hline$F$ & 1,60 Ns & $3,53^{* *}$ & $1,03^{\mathrm{NS}}$ & $5,51 * *$ & $2,07^{\mathrm{NS}}$ & $0,61^{\mathrm{NS}}$ & \\
\hline
\end{tabular}

Médias seguidas de mesma letra, maiúscula nas colunas ou minúscula nas linhas, não diferem entre si pelo teste de Tukey a $5 \%$ de probabilidade. ${ }^{N S}$ não significativo. $\mathrm{B}=$ bom, $\mathrm{D}=$ duvidoso, $\mathrm{I}=$ insuficiente, $\mathrm{MB}=$ muito bom, $\mathrm{S}=$ suficiente, $\mathrm{P}=$ péssimo, $\mathrm{M}=$ mau, pela classificação de Rolim (1989).

o qual apresentou os resultados menos satisfatórios para I. grandifolia (35,83\%), I. hederifolia $(38,33 \%)$ e I. quamoclit (41,67\%), que variaram de mau $(\mathrm{M})$ a péssimo $(\mathrm{P})$, enquanto para as outras plantas daninhas os níveis de controle foram insuficientes (I).

Não houve diferenças estatísticas no desdobramento aos 150 DAT para o controle de I. nil, porém, pela escala de notas, as misturas sulfentrazone + diuron + hexazinone e sulfentrazone + amicarbazone receberam controle bom (B). Para I. hederifolia, apesar de somente clomazone + hexazinone apresentar diferenças com menor valor, o controle bom (B) foi observado com a aplicação de sulfentrazone. Ipomoea quamoclit teve os melhores controles (muito bom - MB) com a utilização de sulfentrazone, sulfentrazone + diuron + hexazinone e sulfentrazone + amicarbazone. Merremia aegyptia recebeu a maior nota (bom - B) com a aplicação do tratamento sulfentrazone + amicarbazone. 
Observou-se redução geral na eficácia de controle de todos os herbicidas sobre as espécies estudadas aos 150 DAT, especialmente ao comparar os valores atribuídos com aqueles aos 30 DAT. Assim, se for considerado que o ciclo da soqueira de cana-de-açúcar pode ser finalizado entre 300 e 360 dias (Azania et al., 2005), que 150 DAT representam metade do ciclo da cultura e que as espécies de Ipomoea spp. e Merremia spp. germinam e desenvolvemse mesmo com o solo sombreado pela cultura (Martins et al., 1999), produzem quantidades elevadas de sementes e apresentam fluxos de emergência escalonados, torna-se importante refletir sobre a condução de experimentos com uma segunda aplicação de herbicidas. Estes experimentos deverão contar com produtos em pós-emergência e, de preferência, com modo de ação diferente dos aplicados anteriormente, além da utilização de implementos específicos para aplicação em cana-de-açúcar com altura mais elevada - a exemplo de trâmpulos equipados com barra de pulverização e a devida análise econômica.

\section{LITERATURA CITADA}

AZANIA, A. A. P. M. et al. Interferência da palha da cana-deaçúcar (Saccharum spp.) na emergência de espécies de plantas daninhas da família Convolvulaceae. Planta Daninha, v. 20, n. 2, p. 207-212, 2002.

AZANIA, C. A. M. Controle de plantas infestantes com diferentes herbicidas e sua seletividade às soqueiras de cana-de-açúcar (Saccharum spp.). 2000. 60 f. Dissertação (Mestrado em Produção Vegetal) - Universidade Estadual Paulista, Jaboticabal, 2000.

AZANIA, C. A. M.; AZANIA, A. A. P. M. Cana: limpa e lucrativa. Cader. Técn. Cultivar Grandes Cult., n. 79, p. 3-10, 2005.

BRASIL. Ministério da Agricultura, Pecuária e Abastecimento. Agrofit - Sistema de Agrotóxicos Fitossanitários. Brasília: 2007. Disponível em: <http:// extranet.agricultura.gov.br/agrofit_cons/ principal_agrofit_cons $>$. Acesso em: 14 abr. 2008.

CENTRO INTEGRADO DE INFORMAÇÕES AGROMETEOROLÓGICAS - CIIAGRO. Quadro de temperatura mensal. Disponível em: $<$ http: www.ciiagro.sp.gov.br/ciiagroonline/Quadros/ qTmedPeriodo.asp.com.br>. Acesso em: 01 jul. 2008

CORREIA, N. M.; DURIGAN, J. C. Emergência de plantas daninhas em solo coberto de palha de cana-de-açúcar.

Planta Daninha, v. 22, n. 1, p. 11-17, 2004.
DEFELICE, M. S. Tall morningglory, Ipomoea purpurea (L.) Roth - Flower or Foe? Weed Technol., v. 15, p. 601-606, 2001.

ELMORE, C. D.; HURST, H. R.; AUSTIN, D. F. Biology and control of morningglories (Ipomoea spp.). Weed Sci., v. 5, p. 83-114, 1990.

KISSMANN, K. G.; GROTH, D. Plantas infestantes e nocivas. 2.ed. São Paulo: BASF Brasileira, 1999. v. 2. 978 p.

LAMOREAUX, R. J.; JAIN, R.; HESS, F. D. Efficacy of dimethenamid, metolachlor and encapsulated alachlor in soil covered with crop residue. Bringhton Crop Protec. Conf. Weeds, v. 3, p. 1015-1020, 1993.

LOCKE, M. A.; BRYSON, C. T. Herbicide-soil interaction in reduced tillage and plant residue management systems. Weed Sci., v. 45, p. 307-20, 1997.

MARTINI, G.; DURIGAN, J. C. Influência do teor de água na superfície do solo sobre a eficácia e seletividade do flazasulfuron, na cultura de cana-de-açúcar. Planta Daninha, v. 22 , n. 2 , p. $259-267,2004$.

MARTINS, D. et al. Emergência em campo de dicotiledôneas infestantes em solo coberto com palha de cana-de-açúcar. Planta Daninha, v. 17, n. 1, p. 151-161, 1999.

MEDEIROS, D.; CHRISTOFFOLETI, P. J. Efeito da palha de cana-de-açúcar em áreas de colheita mecanizada sem queima sobre a infestação de plantas daninhas e eficácia de herbicidas. In: PRADO, R.; JORRÍN, J. V. Uso de herbicidas en la agriculturadel siglo XXI. Córdoba: Universidad de Córdoba, 2001. p. 599-605.

MONQUERO, P. A. et al. Eficácia de herbicidas em diferentes quantidades de palha de cana-de-açúcar no controle de Euphorbia heterophylla. Planta Daninha, v. 25, n. 3, p. 613-619, 2007.

NEGRISOLI, E. et al. Controle de plantas daninhas pelo amicarbazone aplicado na presença de palha de cana-deaçúcar. Planta Daninha, v. 25, n. 3, p. 603-611, 2007.

NEGRISOLI, E. et al. Eficácia do sulfentrazone em diferentes doses associado à palha de cana-de-açúcar com ou sem chuva após a aplicação no controle de plantas daninhas. In: CONGRESSO BRASILEIRO DA CIÊNCIA DAS PLANTAS DANINHAS, 24., 2004, São Pedro. Anais... São Pedro: 2004. $150 \mathrm{p}$.

ROLIM, J. C. Proposta de utilização da escala EWRC modificada em ensaios de campo com herbicidas. Araras: IAA/PLANALSUCAR. Coordenadoria Regional Sul, 1989. 3 p. (Não Publicado)

Planta Daninha, Viçosa-MG, v. 27, n. 4, p. 841-848, 2009 
SIEBERT, J. D.; GRIFFIN, J. L.; JONES, C. A. Red morninglory (Ipomoea coccinea) control with 2,4-D and alternative herbicides. Weed Technol., v. 18, p. 38-44, 2004.

SIMONI, F. et al. Eficácia de imazapic e sulfentrazone sobre Cyperus rotundus em diferentes condições de chuva e palha de cana-de-açúcar. Planta Daninha, v. 24, n. 4, p. 769-778, 2006.
UNICA: Portal do Agronegócio - Safra de cana-de-açúcar 2008/09. Disponível em: < http://

www.portaldoagronegócio.com.br>. Acesso em: 30 abr. 2008.

WALKER, A.; MOON, Y.; WELCH., S. J. Influence of temperature, soil moisture and soil characteristics on the persistence of alachlor. Pest. Sci., v. 35, n. 1, p. 109-116, 1992. 